\title{
Amniotic fluid emboli update
}

\author{
Jeremy Whiting MD
}

\section{INTRODUCTION}

Amniotic fluid embolism (AFE) is a devastating syndrome unique to obstetrics. Although two pathologists from the University of Chicago published the original case series in $1941^{1}$, most of the current research on AFE is published in journals of obstetrics and gynecology. However, given the sudden, catastrophic, and life-threatening nature of AFE, critical care specialists are routinely consulted. Even with multidiscipline care in intensive care units, the mortality ranges from $20 \%$ to $90 \%$, depending on the case definition. This article updates critical care physicians on the recent literature and treatment for this condition.

\section{EPIDEMIOLOGY-INCIDENCE AND RISK FACTORS}

Several population-based studies have been performed to determine the incidence and risk factors for AFE. The incidence and mortality rates are summarized in Table 1 for four large studies done in the U.S., Canada, U.K., and Australia. ${ }^{2,5}$ These results highlight the rarity of AFE and the high mortality rates with this diagnosis. Unfortunately, several flaws in methodology undermine these results. For example, the U.K. Obstetric Surveillance System still considers a postmortem finding of fetal squames or hair in the lungs as a positive diagnosis of $\mathrm{AFE}^{2}$, despite evidence that these findings are not unique markers for this diagnosis (see "Pathogenesis"). The other three studies used ICD-9/ICD-10 discharge diagnoses, placing the responsibility for the correct diagnosis on the provid-

Corresponding author: Jeremy Whiting MD

Contact Information: jeremy.whiting@readinghealth.org DOI: 10.12746/swrccc2016.0415.201 er rather than using consistent diagnostic criteria. ${ }^{3-5}$ Clark summarized the current data on incidence in a 2014 review and suggested that 1 in 40,000 deliveries is a reasonable figure. ${ }^{6}$

Several risk factors have been identified, but these large studies disagree on key findings. Table 2 summarizes the risk factors found in four population-based studies. ${ }^{2-5}$ Risk factors identified in at least three of the four studies were maternal age over 35, induction of labor, placenta previa, cesarean delivery, instrumental vaginal delivery, and placental abruption.

\section{Pathogenesis}

In their original 1941 case series with eight patients, Steiner and Lushbaugh suggested that amniotic fluid containing fetal squames, trophoblasts, and other debris entered the maternal circulation and obstructed pulmonary vessels. ${ }^{1}$ They thought that this triggered an inflammatory reaction that produced an anaphylaxis-like shock. However, more recent studies have focused on anaphylactoid shock and discounted the importance of physical emboli, since current evidence indicates that amniotic fluid and debris commonly enter the maternal circulation. ${ }^{7,8}$ The anaphylactoid response theory has gained the most support. Exposure to an unknown agent(s) during labor and delivery causes a non-IgE-mediated anaphylaxis-like response. ${ }^{9}$ Several studies have reported an increase in serum tryptase in AFE cases, indicating mast cell degranulation in these patients. ${ }^{10,11}$ Consequently, Clark et al proposed changing the name of AFE to anaphylactoid syndrome of pregnancy, but this suggestion did not replace AFE. ${ }^{9}$ Another theory involves complement activation, since patients with AFE have significantly lower levels of C3 and C4 when compared with postpartum controls. ${ }^{12,13}$ This suggests that the classical pathway of complement is activated 
Table 1 Incidence and mortality in amniotic fluid embolism

\begin{tabular}{|l|l|l|l|l|}
\hline & Country & $\begin{array}{l}\text { Number of } \\
\text { births con- } \\
\text { sidered }\end{array}$ & $\begin{array}{l}\text { Incidence per 100,000 } \\
\text { deliveries (95\% confidence } \\
\text { interval) }\end{array}$ & $\begin{array}{l}\text { Fatality rate among } \\
\text { identified cases }\end{array}$ \\
\hline $\begin{array}{l}\text { Fitzpatrick } \\
\mathbf{2 0 1 6}^{2}\end{array}$ & U.K. & $7,001,438$ & $1.7(1.4-2.1)$ & $19 \%$ \\
\hline $\begin{array}{l}\text { Abenhaim } \\
\mathbf{2 0 0 8}^{3}\end{array}$ & U.S. & $2,940,362$ & $7.7(6.7-8.7)$ & $22 \%$ \\
\hline Kramer & Canada & $4,508,462$ & 2.5 (Unspecified) & $27 \%$ \\
\hline $\mathbf{2 0 1 2}^{4}$ & Australia & 606,393 & $3.3(1.9-4.7)$ & $35 \%$ \\
\hline Roberts & & & & \\
\hline $\mathbf{2 0 1 0}$
\end{tabular}

Table 2 Risk factors in amniotic fluid embolism

\begin{tabular}{|c|c|}
\hline Risk factors identified in more than 1 population study & Risk factors identified in only 1 population study \\
\hline $\begin{array}{l}\text { Maternal age over } 35^{2,3,4,5} \\
\text { Induction of labor }{ }^{2,4,5} \text { (see note A) } \\
\text { Multiple pregnancy }{ }^{2,4} \\
\text { Placenta previa }{ }^{2,3,4,5} \\
\text { Cesarean delivery } 2,3,4,5 \text { (see note B) } \\
\text { Instrumental vaginal delivery }{ }^{2,3,4,5} \text { (see note C) } \\
\text { Placental abruption }{ }^{3,4,5} \\
\text { Preeclampsia and eclampsia } \\
\text { Fetal distress }\end{array}$ & $\begin{array}{l}\text { Black race and other minorities }{ }^{3} \\
\text { Grand multiparity } \\
\text { Uterine or cervical trauma } \\
\text { Polyhydramnios }{ }^{4} \\
\text { Premature rupture of membranes } \\
\text { Artificial rupture of membranes } \\
\text { Manual removal of placenta }\end{array}$ \\
\hline
\end{tabular}

Notes

A. One study showed that Induction of labor was only a risk factor for "medical induction of labor" with no statistically significant risk to "surgical induction of labor", and another study found risk was only with "induction using vaginal prostaglandin" with no statistically significant risk to the use of oxytocin. ${ }^{5}$

B. One study found cesarean delivery was only a risk factor after labor, with no statistically significant risk to cesarean without labor. ${ }^{5}$

C. In one study, the risk to instrumental vaginal delivery was limited to the use of forceps, with vacuum delivery falling just outside statistical significance $(\mathrm{p}=0.06){ }^{3}$ 
by fetal antigens, but alternative pathways could also be activated by anaphylatoxic peptides. ${ }^{14}$

These patients often have initial brief periods of pulmonary and systemic hypertension. Then severe left ventricular dysfunction and hypotension develop, probably secondary to myocardial hypoxemia and/or coronary vasospasm. ${ }^{6}$ Intrapulmonary shunting causes acute severe hypoxemia and a syndrome consistent with ARDS. If the patient survives the cardiac arrest, coagulopathy usually develops with severe disseminated intravascular coagulation and the potential for diffuse bleeding, especially at surgical sites. Experts suggest that this syndrome resembles anaphylactic shock or endotoxin mediated shock and that it represents an abnormal host response to foreign antigens rather than just an embolic event which obstructs vessels.

\section{Clinical presentation}

The classic triad of AFE is sudden hypoxia, hypotension, and coagulopathy in the setting of labor and delivery. Cardiac arrest is the most feared complication, which may develop quickly at presentation; the mechanism for arrest can include asystole, pulseless electrical activity, and ventricular fibrillation/ tachycardia. Fetal distress, identified as a sudden, unexplained deterioration in fetal heart rate pattern, is another potential sign. Patients can also develop seizures, acute confusion, and coma. ${ }^{15}$ Amniotic fluid embolism is a clinical diagnosis, and the time demands for immediate management limit evaluation. ${ }^{6}$ If the patient survives the acute cardiac decompensation, laboratory tests usually show a consumptive coagulopathy with fibrinogen levels $<100 \mathrm{mg} / \mathrm{dl}$, prolonged aPTT and PT, and platelets $<100,000 / \mathrm{ml}^{9}{ }^{9}$ Complement activation may also occur in AFE with decreased levels of C3, C4, and C1 esterase inhibitor. ${ }^{13,16 .}$

\section{TREATMENT}

The Society for Maternal-Fetal Medicine (SMFM) published a clinical guideline for treatment of AFE in $2016 .{ }^{17}$ Treatment is largely supportive and mainly consists of treatment for biventricular failure and respiratory failure. This usually includes mechanical ventilation, crystalloid fluid administration, vasopressors, and inotropic agents. However, excessive fluid resuscitation is not recommended. Instead, early administration of norepinephrine and/or vasopressin to maintain blood flow and perfusion is advised. Inotropes, such as dobutamine, are used to treat the right ventricular failure.

These patients often need blood product replacement for bleeding from their coagulopathy. Fresh frozen plasma (FFP) and cryoprecipitate are indicated for prolonged PTs, aPTTs, and INRs and for fibrinogen level less than $100 \mathrm{mg} / \mathrm{dL}$. Platelet transfusion is needed for platelet counts $<50,000 / \mathrm{mm}^{3}$. In cases with acute massive bleeding, hemostasis control with $1: 1: 1$ ratio of packed red blood cells, platelets, and FFP is recommended without waiting for laboratory results. ${ }^{17}$ Hemodialysis with plasmapheresis and extracorporeal membrane oxygenation with intra-aortic balloon counterpulsation have been reported with successful outcomes in treating AFE patients with cardiovascular collapse. ${ }^{18,19}$ Management by a multidisciplinary team is needed and should include specialists in critical care, anesthesia, respiratory therapy, and maternal-fetal medicine.

For patients in cardiac arrest, ACLS and BLS protocols should be followed. There is a concern about the development of an electric arc when electric cardioversion shock is applied and fetal monitors are connected. Therefore, it is preferred to remove the fetal monitoring while CPR is ongoing. However, electric cardioversion should not be delayed when indicated regardless of presence of other monitors. ${ }^{17}$ Normal CPR protocols can be followed with the exception that if the patient is undelivered, lateral displacement of the uterus can reduce aortocaval compression. Although the evidence is weak, immediate delivery by cesarean section after four minutes of unsuccessful CPR has been suggested as the goal. This recommendation depends on the viability of the fetus, but the most current SMFM guideline suggests immediate delivery in a fetus $\geq 23$ weeks. ${ }^{17}$

Uterine atony is a well-known complication of AFE and should be immediately treated with utero- 
tonics, such as oxytocin, ergots, and prostaglandins. Severe cases may require uterine tamponade, bilateral uterine artery ligation, or hysterectomy. However, other causes of uterine bleeding should be excluded and treated accordingly. ${ }^{20}$

\section{OUtCOMES}

Outcomes for patients with AFE are poor. As noted in Table 1, AFE is commonly a fatal condition with mortality rates ranging from $20-90 \% .^{2-5}$ Mortality rates exceed $90 \%$ in patients who present with cardiac arrest. Amniotic fluid embolus ranks as the first, second, or third most common cause of maternal death, depending on the country; it is the second most common cause in the U.S. and Canada. ${ }^{8}$ Morbidity for both the mother and the neonate is high in survivors. Statistics vary widely, but the latest U.K. Obstetric Surveillance System figures showed that $7 \%$ of AFE survivors had permanent neurologic injury in the mother. ${ }^{2}$ Infant outcomes include an increased risk for stillbirth, asphyxia, mechanical ventilation, bacterial sepsis, seizures, and long length of hospital stays. ${ }^{4}$

Author Affiliation: Jeremy Whiting is a resident in Obstetrics and Gynecology at Reading Hospital, Reading, PA.

Received: 5/4/2016

Accepted: $7 / 10 / 2016$

Reviewers: Jennifer Phy DO

Published electronically: 04/15/2016

Conflict of Interest Disclosures: None

\section{REFERENCES}

1. Steiner PE, Lushbaugh CC. Maternal pulmonary embolism by amniotic fluid as a cause of obstetric shock and unexpected deaths in obstetrics. JAMA 1941; 117:1245-51.

2. Fitzpatrick KE, Tuffnell D, Kurinczuk JJ, Knight M. Incidence, risk factors, management and outcomes of amnioticfluid embolism: a population-based cohort and nested casecontrol study. BJOG 2016; 123:100-109.

3. Abenhaim HA, Azoulay L, Kramer MS, et al. Incidence and risk factors of amniotic fluid embolisms: a populationbased study on 3 million births in the United States. Am J Obstet Gynecol 2008; 199:49.e1-49.e8.

4. Kramer M, Rouleau J, Liu S, Bartholomew S, Joseph K for the Maternal Health Study Group of the Canadian Perinatal Surveillance System. Amniotic fluid embolism: incidence, risk factors, and impact on perinatal outcome. BJOG 2012; 119:874-879.

5. Roberts C, Algert C, Knight M, Morris J. Amniotic fluid embolism in an Australian population-based cohort. BJOG 2010; 117:1417-1421.

6. Clark SL. Amniotic fluid embolism. Obstet Gynecol 2014 Feb; 123(2 Pt 1):337-48.

7. Clark SL, Pavlova Z, Horenstein J, Phelan JP. Squamous cells in the maternal pulmonary circulation. Am J Obstet Gynecol 1986; 154:104-6.

8. Conde-Agudelo A, Romero R. Amniotic fluid embolism: an evidence-based review. Am J Obstet Gynecol 2009 Nov; 201(5):445.e1-13.

9. Clark SL, Hankins GDV, Dudley DA, Dildy GA, Porter TF. Amniotic fluid embolism: analysis of the national registry. Am J Obstet Gynecol 1995; 172:1158-67.

10. Fineschi V, Riezzo I, Cantatore S, Pomara C, Turillazzi E, Neri M. Complement C3a expression and tryptase degranulation as promising histopathological tests for diagnosing fatal amniotic fluid embolism. Virchows Arch 2009; 454:283-290.

11. Nishio $H$, Matsui $K$, Miyazaki $T$, Tamura $A$, Iwata $M$, Suzuki K. A fatal case of amniotic fluid embolism with elevation of serum mast cell tryptase. Forensic Sci Int 2002; 126:53-56.

12. Benson MD. A hypothesis regarding complement activation and amniotic fluid embolism. Med Hypotheses 2007; 68(5):1019-25.

13. Benson MD, Kobayashi H, Silver RK, Oi H, Greenberger PA, Terao T. Immunologic studies in presumed amniotic fluid embolism. Obstet Gynecol 2001; 97:510-514.

14. Busardò FP, Frati P, Zaami S, Fineschi V. Amniotic fluid embolism pathophysiology suggests the new diagnostic armamentarium: $\beta$-tryptase and complement fractions $\mathrm{c} 3$-c4 are the indispensable working tools. International Journal of Molecular Sciences 2015; 16(3):6557-6570. 
15. Rath WH, Hoferr S, Sinicina I. Amniotic fluid embolism: an interdisciplinary challenge: epidemiology, diagnosis and treatment. Dtsch Arztebl Int 2014 Feb 21; 111(8):126-32.

16. Tamura N, Kimura S, Farhana M, Uchida T, Suzuki K, Sugihara K, Itoh H, Ikeda T, Kanayama N. C1 esterase inhibitor activity in amniotic fluid embolism. Crit Care Med 2014 Jun; 42(6):1392-6.

17. Society for Maternal-Fetal Medicine (SMFM) with the assistance of Pacheco LD, Saade G, et al. Amniotic fluid embolism: diagnosis and management. Am J Obstet Gynecol 2016 (in press).

18. Kaneko Y, Ogihara T, Tajima H, Mochimaru F. Continuous hemodiafiltration for disseminated intravascular coagulation and shock due to amniotic fluid embolism: report of a dramatic response. Intern Med. 2001 Sep. 40(9):945-7.

19. Hsieh YY, Chang CC, Li PC, Tsai HD, Tsai CH. Successful application of extracorporeal membrane oxygenation and intra-aortic balloon counterpulsation as lifesaving therapy for a patient with amniotic fluid embolism. Am J Obstet Gynecol. 2000 Aug. 183(2):496-7

20. Matsuda Y, Kamitomo M. Amniotic fluid embolism: a comparison between patients who survived and those who died. J Int Med Res 2009; 37:1515-21. 